\title{
O papel da microbiota bacteriana intestinal de abelhas eussociais: uma revisão de
}

\section{literatura}

\author{
The role of the gut microbiota of eusocial bees: a literature review \\ El papel de la microbiota intestinal de las abejas eusociales: una revisión de la literatura
}

Recebido: 10/10/2021 | Revisado: 18/10/2021 | Aceito: 21/10/2021 | Publicado: 24/10/2021

\author{
Suziane Pinto Rodrigues \\ ORCID: https://orcid.org/0000-0002-5991-7716 \\ Universidade Federal do Amazonas, Brasil \\ E-mail: rodrigues.suzi1996@gmail.com \\ José Carlos Ipuchima da Silva \\ ORCID: https://orcid.org/0000-0002-3628-7985 \\ Universidade do Estado do Amazonas, Brasil \\ E-mail: carlos.silva.jcids@gmail.com \\ Thaissa Cunha de Oliveira \\ ORCID: https://orcid.org/0000-0003-3124-8124 \\ Universidade Federal do Amazonas, Brasil \\ E-mail: thaissa.olcunha@gmail.com \\ Larissa Ipuchima da Silva \\ ORCID: https://orcid.org/0000-0003-3231-1041 \\ Universidade Federal do Amazonas, Brasil \\ E-mail: larissa.ipuchima@gmail.com \\ Nadionara Costa Menezes \\ ORCID: https://orcid.org/0000-0002-9716-0822 \\ Universidade do Estado do Amazonas, Brasil \\ E-mail: nadionaracosta@gmail.com
}

\begin{abstract}
Resumo
As abelhas apresentam complexas interações simbióticas com microrganismos, os quais em troca de abrigo e alimento, fornecem a seus hospedeiros diversos benefícios, como metabolização de alimentos, desintoxicação, fornecimento de nutrientes essenciais, proteção contra espécies invasoras e patógenos, modulação do desenvolvimento e imunidade. Assim, essas relações simbióticas muitas vezes são essenciais para a sobrevivência das abelhas. Objetivo deste estudo, é apresentar o papel da microbiota intestinal bacteriana de abelhas eussociais e a importância que ela exerce em seu hospedeiro. Destacamos também, quais são estas bactérias e como elas são adquiridas. Foram usadas as bases de dados do PubMed, Periódicos da CAPES e Ferramenta de Pesquisa Acadêmica (Scholar Google), em um período de tempo compreendido de 2009 a 2020, relacionados ao papel da microbiota intestinal de abelhas eussociais. Ao todo foram encontrados 28 artigos, os dados obtidos foram tabelados expondo as espécies hospedeira e os benefícios que a microbiota bacteriana exerce. Além disso, foram selecionadas as principais atividade exercidas por esses simbiontes intestinais e decorrido sobre cada uma, explicando, com base em estudos relacionados, como funcionam.
\end{abstract}

Palavras-chave: Microbiota de abelhas; Simbiontes; Microbiota bacteriana; Abelhas eussociais.

\begin{abstract}
Bees have complex symbiotic interactions with microorganisms, which, in exchange for shelter and food, provide their hosts with several benefits, such as food metabolism, detoxification, supply of essential nutrients, protection against invasive species and pathogens, modulation of development and immunity. Thus, these symbiotic relationships are often essential for the bees' survival. The aim of this study is to present the role of the bacterial intestinal microbiota of eusocial bees and the importance it plays in its host. We also highlight what these bacteria are and how they are acquired. The databases of PubMed, CAPES Journals and Academic Research Tool (Scholar Google) were used, in a period of time from 2009 to 2020, related to the role of the intestinal microbiota of eusocial bees. Altogether 28 articles were found, the data obtained were tabulated exposing the host species and the benefits that the bacterial microbiota exerts. In addition, the main activities performed by these intestinal symbionts were selected and each one was discussed, explaining, based on related studies, how they work.
\end{abstract}

Keywords: Bee microbiota; Symbionts; Bacterial microbiota; Eusocial bees.

\section{Resumen}

Las abejas tienen complejas interacciones simbióticas con los microorganismos, que a cambio de refugio y alimento, brindan a sus hospederos varios beneficios, como metabolismo de los alimentos, desintoxicación, suministro de 
nutrientes esenciales, protección contra especies invasoras y patógenos, modulación del desarrollo e inmunidad. Por lo tanto, estas relaciones simbióticas suelen ser esenciales para la supervivencia de las abejas. El objetivo de este estudio es presentar el papel de la microbiota intestinal bacteriana de las abejas eusociales y la importancia que juega en su hospedador. También destacamos qué son estas bacterias y cómo se adquieren. Se utilizaron las bases de datos de PubMed, CAPES Journals y Academic Research Tool (Scholar Google), en un período de tiempo de 2009 a 2020 , relacionado con el papel de la microbiota intestinal de las abejas eusociales. En total se encontraron 28 artículos, los datos obtenidos se tabularon exponiendo las especies hospedadoras y los beneficios que ejerce la microbiota bacteriana. Además, se seleccionaron las principales actividades que realizan estos simbiontes intestinales y se discutió cada una, explicando, en base a estudios relacionados, cómo funcionan.

Palabras clave: Microbiota de abejas; Simbiontes; Microbiota bacteriana; Abejas eusociales.

\section{Introdução}

As abelhas eussociais são aquelas que apresentam colônias com ciclo colonial perene e castas de rainha e operárias altamente especializadas. Elas pertencem a família Apidae e compreendem três tribos distintas, sendo estas a tribo Meliponini, também conhecidas como abelhas sem ferrão, tribo Apini, abelhas do gênero Apis, contendo a espécie mais conhecida, Apis mellifera, e tribo Bombini, onde estão classificadaes abelhas do gênero Bombus, sendo que esta última é denominada primitivamente eussociais, pois formam pequenas colônias com ciclo colonial anual e castas menos especializadas (Goulson, 2010; Michener, 2000; 2007; 2013).

Essas abelhas têm grande importância econômica e ambiental, fornecem ao mundo serviços ecossistêmicos amplos como polinizadores de culturas equivalentes a cerca de $€ 150$ bilhões e são responsáveis por cerca de $9,5 \%$ de toda a produção de alimentos utilizadas na alimentação humana (Gallai et al., 2008). Diante disso, o declínio crescente da população de abelhas tornou-se uma preocupação mundial, sendo estudadas formas de minimizar estas perdas.

Assim, o estudo do papel e entendimento dos microrganismos associados a elas é cada vez mais consensual, pois fazem parte dos elementos chave para a homeostase, tanto do ninho quanto do indivíduo (Kwong et al., 2017; Khan et al., 2020). Dessa forma, objetivamos apresentar o papel da microbiota intestinal bacteriana de abelhas eussociais e a importância que ela exerce em seu hospedeiro, destacando também, quem são essas bactérias e como elas são adquiridas.

\section{Metodologia}

Esta revisão foi realizada de forma sistemática relacionando o papel exercido pela microbiota intestinal bacteriana de abelhas eussociais. Os dados foram coletados, utilizando abordagem quali/quantitativa, através de artigos nas seguintes bases de dados: PubMed, Periódicos da CAPES e a Ferramenta de Pesquisa Acadêmica (Scholar Google). A busca foi desenvolvida utilizando-se o descritor: microbiota bacterina intestinal de abelhas sociais, nos bancos de dados citados. Na busca inicial foram considerados os títulos e os resumos dos artigos para a seleção ampla de prováveis trabalhos de interesse, sendo destacados os resumos dos artigos que não tinham texto acessível e os textos completos dos artigos. O recorte temporal utilizado foi entre os anos de 2009-2020 (dando preferência por publicações atuais), sendo excluídos aquelas que não atendiam aos critérios estabelecidos (Ercole, Melo \& Alcoforado, 2014).

\section{Resultados e Discussão}

\subsection{Bactérias associadas ao intestino de abelhas}

Nas abelhas, assim como na maioria dos animais, a seção distal do intestino (íleo e reto) abriga a maior parte da comunidade bacteriana, isso se dá devido à presença abundante de alimentos não digeridos pelo hospedeiro, depositados nessa região, tornando-se fontes acessíveis de energia, carbono e nitrogênio disponíveis para a microbiota, formando o lar de uma comunidade relativamente simples, porém altamente específica (Bonilla-Rosso \& Engel, 2018). 
A microbiota intestinal é composta por cinco membros principais: Snodgrassella alvi, Gilliamella apícola, Bifidobacterium spp., Lactobacillus Firm-4 e Lactobacillus Firm-5, sendo predominantes nas três tribos eussociais (Apini, Bombini e Meliponini), sugerindo que parte da comunidade do microbioma intestinal de abelhas eussociais é composta por um conjunto central de bactérias (core) bem estabelecidas, e outros membros denominados de transientes, totalizando um pequeno número de 8 grupos bacterianos (Figura 1) (Martinson et al., 2011; Moran et al., 2012; Kwong et al., 2017). Sendo em sua maioria anaeróbias facultativas ou microaerófilas, pouco frequentes em ambientes da colônia e provavelmente dependem das interações sociais para serem transmitidos de hospedeiro para hospedeiro (Kwong \& Moran, 2016; Raymann \& Moran, 2018).

Figura 1. Composição e organização espacial das comunidades bacterianas no intestino das abelhas Apis mellifera.

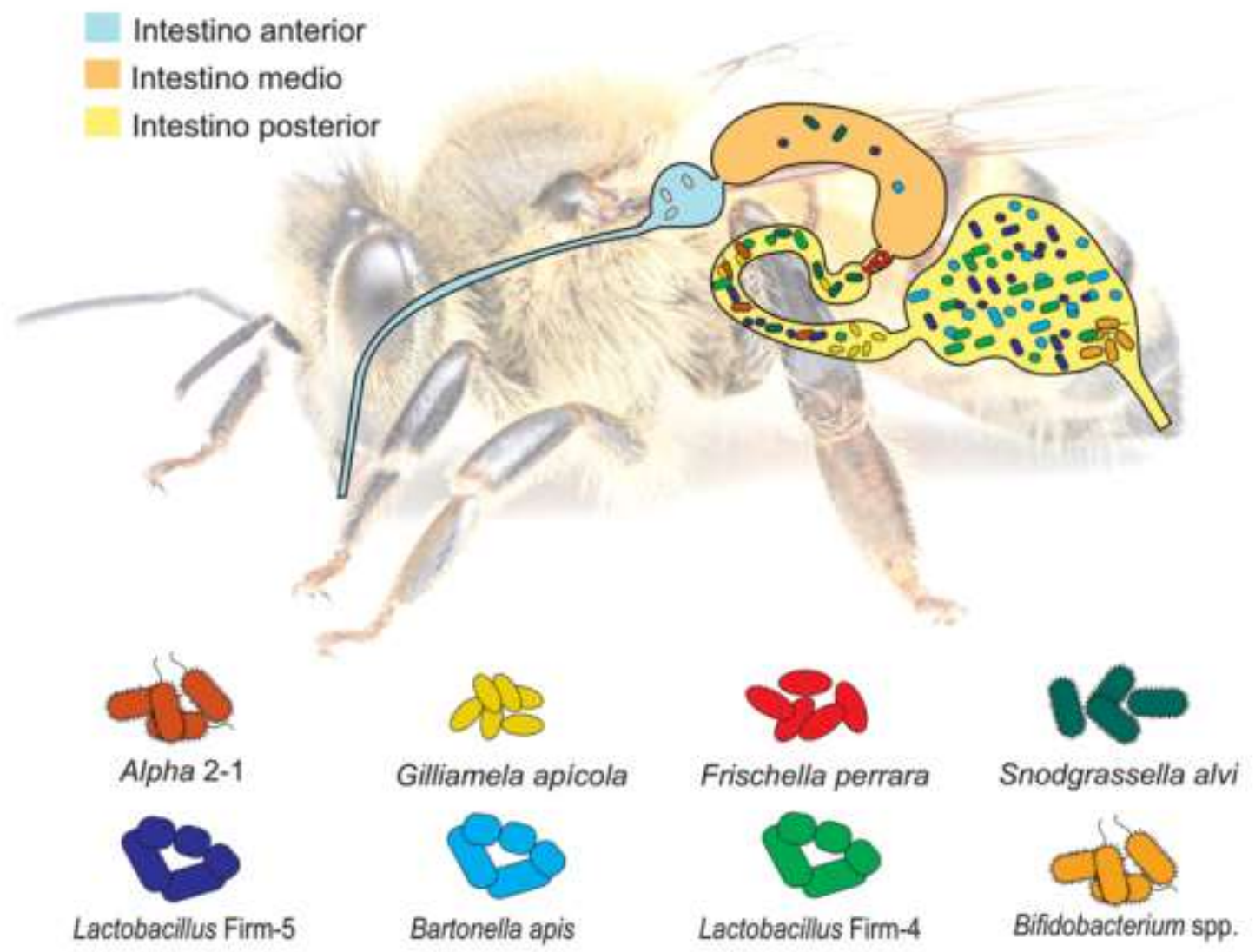

*A composição da microbiota em uma típica abelha operária adulta Apis mellifera e a localização de bactérias nos diferentes compartimentos do intestino. O intestino anterior e médio é composto por poucas bactérias, do néctar e do ambiente da colmeia, já o intestino posterior detém maior abundância de microrganismos adquiridos através do contato social com outros membros da colmeia.

Fonte: Autores.

Alguns filotipos estudados parecem ser específicos, como por exemplo Bartonella apis e Frischella perrara em abelhas Apis melifera, Bombiscardovia e Schmidhempelia em abelhas Bombus e Acetobacter em abelhas sem ferrão (Kwong et al., 2017). Chegando à conclusão, que há compartilhamento da microbiota intestinal, entre abelhas eussociais, sendo esta originária de um ancestral comum de aproximadamente 80 milhões de anos, o que sugere que a microbiota teve origem com o início da eussocialidade, e que de acordo com evolução das tribos, as abelhas foram perdendo e/ou adquirindo uma microbiota específica.

\subsubsection{Aquisição microbiota intestinal bacteriana de abelhas}

O intestino das abelhas eussociais apresenta um ecossistema complexo que envolve várias espécies de simbiontes (fungos, bactérias e protozoários), interagindo em um ambiente dinâmico (Engel et al., 2016). E para garantir esse ambiente, 
são enfrentados diversos desafios para que haja a aquisição e a transmissão de microrganismo às gerações seguintes (Onchuru et al., 2018).

A aquisição e transmissão de microrganismos intestinais foram explorados principalmente em abelhas do gênero Apis, nas quais foi observado que a abundância relativa bacteriana associada ao intestino muda drasticamente em cada estágio de vida da abelha (Moran, 2015). A partir de um ovulo fecundado e depositado em uma célula individual, eclodindo em sua forma larval, são alimentadas por abelhas operárias denominadas enfermeiras. Esses alimentos, em sua maioria, estão contaminados por bactérias transientes, não colonizadoras estáveis, que adentram o intestino dessas abelhas. No final do estágio larval, as abelhas enfermeiras constroem um tampo de cera que sela a célula antes da pupação, e nesse processo um septo que separa o intestino médio e posterior é eliminado. Já no final da pupação o exoesqueleto, incluindo o revestimento do intestino, passa por processo de ecdise, eliminando quaisquer bactérias que possa estar presente no intestino. Após a conclusão da metamorfose, a abelha adulta mastiga o tampo de cera e emerge "livre de bactérias intestinais", embora algumas possam ser adquiridas no processo de mastigação do tampo (Cruz-Landim, 2009; Moran, 2015; Kwong \& Moran, 2016).

As abelhas recém emergidas apresentam uma microbiota ainda pouco desenvolvida, sendo adquirida principalmente através da transferência direta de fluidos orais via alimentação boca a boca, como também através das fezes frescas das abelhas enfermeiras, bem como de conteúdo do intestino posterior via alimentação ânus-boca, da transferência por contato direto com material de colmeia contaminado com simbionte, como cera, pólen, mel e célula de cria, além do forrageamento, sendo que os dois últimos casos fazem parte da microbiota transiente (Onchuru et al., 2018; Khan et al., 2020). Também foi observado que em algumas espécies como a Apis mellifera, as rainhas ao fundar uma nova colônia repassam verticalmente simbiontes a seus descendentes (Figura 2) (Martinson et al., 2011; Onchuru et al., 2018; Raymann \& Moran,2018; Khan et al., 2020).

Assim como outros animais, as abelhas eussociais detêm comunidades intestinais características dominadas por linhagens bacterianas, que nunca ou raramente são detectadas fora de seus hospedeiros, sendo restritos ao ambiente intestinal (Kwong et al., 2017; Moran, Ochman \& Hammer, 2019). Enquanto o intestino de abelhas eussociais são dominadas por espécies bacterianas intestinais específicas. Tem sido evidenciado que o intestino de abelhas solitárias é dominado por espécies bacterianas presentes no néctar e em outros ambientes, o que nos leva a crê que o estilo de vida influencia diretamente na transmissão desses simbiontes (Martinson et al., 2011; Mcfrederick et al., 2012).

Figura 2. Principais formas de transmissão de simbiontes intestinais em abelhas Apis mellifera.

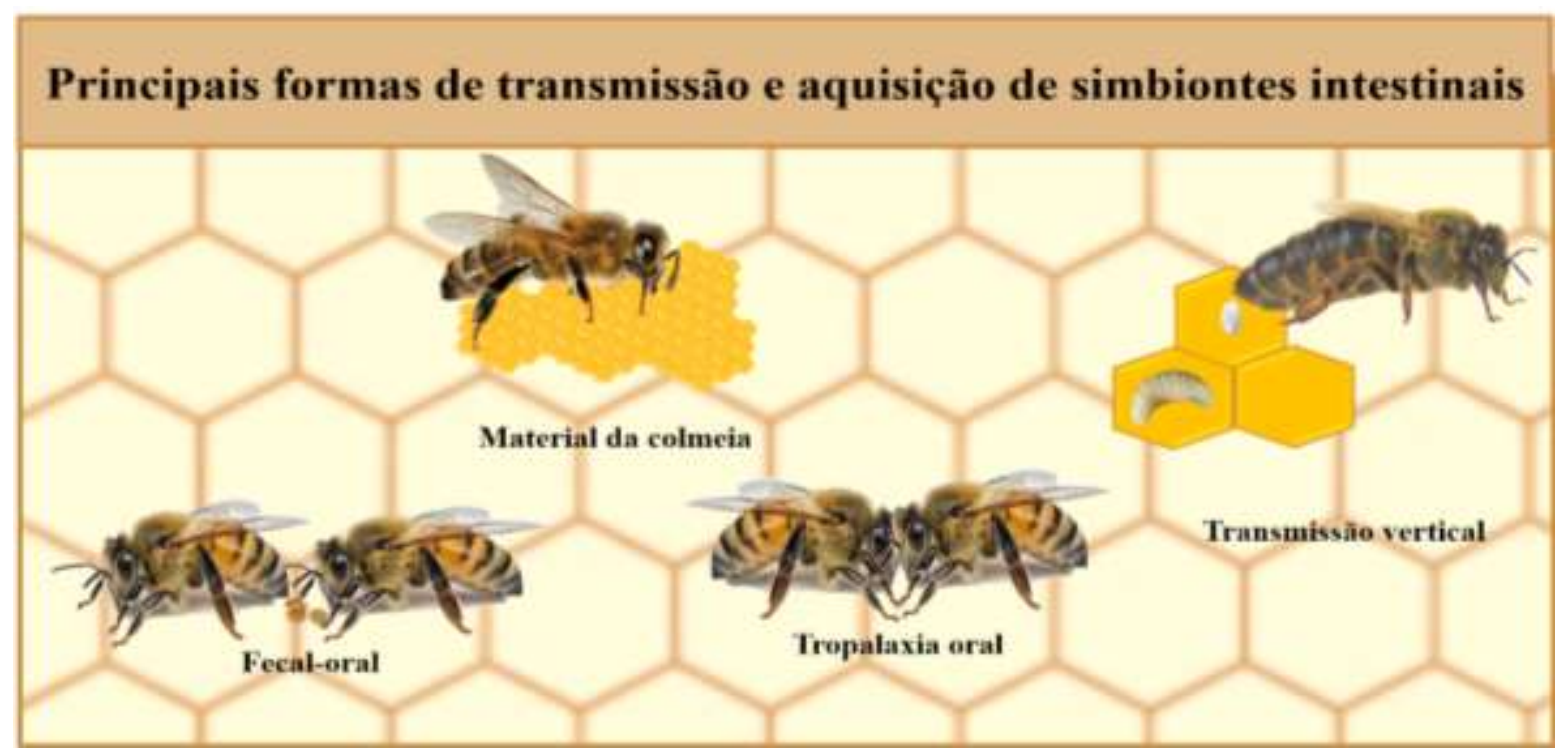

*As operárias recém emergidos não abrigam nenhuma ou muito poucas bactérias intestinais e adquirem a microbiota intestinal normal, principalmente por meio do contato com material fecal, embora outras vias de transmissão também possam ter um papel, como os descritos na imagem. Fonte: Autores. 


\subsection{Papel da microbiota intestinal bacteriana de abelhas}

A rápida expansão da pesquisa sobre microbiomas intestinais foi impulsionada por descobertas nas quais as bactérias intestinais geralmente estão diretamente associadas a saúde de seus hospedeiros (Khan et al., 2020). Especificamente, muitos estudos documentaram déficits de aptidão em animais experimentalmente privados de uma microbiota intestinal normal, seja com antibióticos ou criando indivíduos em ambientes estéreis para evitar a colonização (Ryu et al., 2008; Yun et al., 2018; Zheng et al., 2018). Desta forma, foram encontrados 28 artigos tabelados abaixo (Tabela 1), onde foram observados que hospedeiro pode se beneficiar de sua microbiota intestinal na metabolização de alimentos, nutrição, desintoxicação, proteção contra a invasão por patógenos e desenvolvimento da imunidade.

Tabela 1. O papel da microbiota de abelhas eussociais.

\begin{tabular}{|c|c|c|c|}
\hline $\begin{array}{c}\text { Colonizadores bacterianos } \\
\text { intestinais }\end{array}$ & Espécie hospedeira & Benefício & Referências \\
\hline $\begin{array}{l}\text { Lactobacillus e } \\
\text { Bifidobacterium } \mathrm{sp} .\end{array}$ & $\begin{array}{l}\text { Abelhas sem ferrão (Trigona, } \\
\text { Meliponula bocandeei, Melipona } \\
\text { beecheii). Apis andreniformis, } A . \\
\text { cerana, } \text { A. koschevnikovi, } A . \\
\text { nuluensis, } \text {. } \text {. dorsata, } \text { A. } \\
\text { laboriosa, } \text { A. florea, } \text { } . \\
\text { nigrocincta, } \text { A. mellifera. }\end{array}$ & $\begin{array}{c}\text { Estimulação imunológica, e } \\
\text { consequente promoção da proteção } \\
\text { contra patógenos (larvas de } \\
\text { Paenibacillus e Melisococcus } \\
\text { plutonius). }\end{array}$ & $\begin{array}{l}\text { Forsgren et al., 2010; Vásquez et } \\
\text { al., 2012; Wu et al., 2013; Killer } \\
\text { et al., 2014; Asenjo et al., } 2016 .\end{array}$ \\
\hline Gilliamella sp. & Bombus spp. & $\begin{array}{l}\text { Redução da infecção por Crithidia } \\
\text { bombi }\end{array}$ & $\begin{array}{l}\text { Koch \& Schmid-Hempel, 2011; } \\
\text { Cariveau et al., } 2014 .\end{array}$ \\
\hline Bacillus spp. & Apis cerana japônica & $\begin{array}{l}\text { Inibição do crescimento de um } \\
\text { patógeno bacteriano }(P . \text { larvae })\end{array}$ & Yoshiyama \& Kimura, 2009. \\
\hline $\begin{array}{c}\text { Gilliamella } \\
\text { apicola, Lactobacillus } \\
\text { e Bifidobacterium }\end{array}$ & Apis mellifera e Bombus spp. & $\begin{array}{l}\text { Nutrição das abelhas através do } \\
\text { metabolismo de açúcares, além da } \\
\text { produção de enzimas que } \\
\text { degradam carboidratos e açúcares } \\
\text { tóxicos encontrados na dieta das } \\
\text { abelhas. Tendo papéis importantes } \\
\text { na melhoria das tolerâncias } \\
\text { dietéticas e na manutenção da } \\
\text { saúde de seus hospedeiros. }\end{array}$ & $\begin{array}{l}\text { Bottacini et al., 2012; Engel \& } \\
\text { Martison; Moran, 2012; Engel \& } \\
\text { Moran, 2013; Kwong et al., } \\
\text { 2014; Kwong, Engel, Koch \& } \\
\text { Moran, 2014; Lee et al., 2015; } \\
\text { Zheng et al., 2016; Kešnerová et } \\
\text { al., 2017; Lee, et al., 2018. }\end{array}$ \\
\hline $\begin{array}{l}\text { Comunidade bacteriana } \\
\text { intestinal }\end{array}$ & Apis mellifera & $\begin{array}{l}\text { Estímulo de ganho de peso do } \\
\text { hospedeiro, a sensibilidade à } \\
\text { sacarose do hospedeiro e o } \\
\text { aumento da expressão de genes } \\
\text { relacionados à sinalização } \\
\text { hormonal. }\end{array}$ & Zheng et al., 2017. \\
\hline $\begin{array}{l}\text { Comunidade bacteriana } \\
\text { intestinal }\end{array}$ & Apis mellifera & $\begin{array}{c}\text { Modificação das vias de } \\
\text { desintoxicação dos xenobióticos } \\
\text { do hospedeiro. }\end{array}$ & Wu et al., 2020. \\
\hline $\begin{array}{c}\text { S. alvi, Gilliamella } \\
\text { apicola, Frischella perrara, } \\
\text { Bifidobacterium spp. } \\
\text { e Lactobacillus Firm-4 e } \\
\text { Firm-5 }\end{array}$ & Apis mellifera & $\begin{array}{l}\text { Estímulo à produção de peptídeos } \\
\text { antimicrobiano e consequente } \\
\text { contribuição para o sistema } \\
\text { imunológico inato das abelhas. }\end{array}$ & $\begin{array}{l}\text { Kwong, Mancenid \& Moran, } \\
2017 .\end{array}$ \\
\hline $\begin{array}{l}\text { Comunidade bacteriana } \\
\text { intestinal }\end{array}$ & Apis mellifera & $\begin{array}{l}\text { As alterações da microbiota } \\
\text { intestinal afetam homeostase do } \\
\text { hospedeiro, aumentam } \\
\text { suscetibilidade à invasão de } \\
\text { patógenos. }\end{array}$ & $\begin{array}{l}\text { Kakumannuet et al. 2016; } \\
\text { Schwarz, Moran \& Evans, 2016; } \\
\text { Raymann, Shaffer \& Moran, } \\
\text { 2017; Raymann, Bobay \& } \\
\text { Moran, 2018; Motta, Raymann } \\
\text { \& Moran, 2018; Nogrado et al., } \\
\text { 2019. }\end{array}$ \\
\hline Frischella perrara & Apis mellifera & $\begin{array}{l}\text { Estimulação da resposta } \\
\text { imunológica em abelhas. }\end{array}$ & $\begin{array}{l}\text { Engel, Bartlett \& Moran, 2015; } \\
\text { Emery, Schmidt \& Engel, } 2017 .\end{array}$ \\
\hline
\end{tabular}




\subsubsection{Metabolização de alimentos e nutrição}

A microbiota intestinal das abelhas, assim como em humanos, utiliza principalmente carboidratos complexos com substrato para a sua sobrevivência, sendo o pólen e o néctar os principais componentes da dieta das abelhas e principal fonte de aminoácidos, gordura, vitaminas e minerais (Vaudo et al., 2015; Frias et al., 2016). A maioria desses nutrientes é absorvida no intestino médio do hospedeiro, deixando apenas os compostos complexos como celulose, hemicelulose e pectina para serem digeridos pela comunidade microbiana intestinal no intestino posterior (Zheng et al., 2018; 2019).

O papel da microbiota intestinal na degradação de tais componentes da dieta de abelhas e atividades metabólicas estão associadas a membros específicos da comunidade microbiana, como Gilliamella apicola, Lactobacillus e Bifidobacterium spp. (Bottacini et al., 2012; Engel, Martison \& Moran, 2012; Engel \& Moran, 2013; Lee, et al., 2014; Kwong et al., 2014; Zheng et al., 2016; Kešnerová et al., 2017; Lee et al., 2018).

Estudo desenvolvido por Zheng e colaboradores (2017) mostrou que a comunidade intestinal tem impactos marcantes sobre os perfis metabólicos dos compartimentos intestinais e da hemolinfa, sugerindo que as bactérias intestinais degradam polímeros vegetais do pólen e que os metabólitos resultantes contribuem para a nutrição do hospedeiro. Onde foi possível observar a partir de uma comparação entre abelhas gnotobióticas versos abelhas com a comunidade bacteriana convencional, que a microbiota intestinal estimulou o aumento no peso corporal das abelhas, enquanto, abelhas livre de microbiota de microbiota apresentaram-se menores e menos nutridas. Esse comportamento sugere que os microrganismos intestinais podem gerar mudanças no processo de vitalogênese do hospedeiro, além das mudanças na sinalização da insulina e na resposta gustativa.

\subsubsection{Desintoxicação}

As abelhas são expostas diariamente a diversos estressores que elevam suas taxas de mortalidade, sendo esses: estresse ambiental, manejo apícola inadequado, perda de habitat, dietas monótonas e uso indiscriminado de pesticidas e agrotóxicos nas plantações, além dos patógenos (Goulson et al., 2015). Entre estes, a exposição a pesticidas pode ser, dependo das doses aplicadas, letal para estas abelhas. Pois, recentemente foi descoberto que doses subletais de pesticidas afetam o comportamento das abelhas, a capacidade de forrageamento, o aprendizado, o desenvolvimento individual e em colônia (Gill et al., 2012; Henry et al., 2012; Fairbrother et al., 2014).

Entretanto, as abelhas possuem órgãos que fazem o papel de excreção de substâncias tóxicas, sendo que o intestino médio é um dos principais locais de desintoxicação de insetos (Smagghe \& Tirry, 2001). Os pesticidas podem ser absorvidos pelas células epiteliais do intestino médio, onde a maior parte deles é metabolizada antes de ser transportada de volta para o lúmen do intestino médio, através da membrana apical ou na hemolinfa, através da membrana basal (Du Rand et al., 2017).

Sabendo disso, Wu et al. (2020), buscaram investigar o papel da microbiota na desintoxicação de xenobióticos. Para isso foi realizada a comparação de um gene de desintoxicação, o citocromo P450s, tanto em abelhas gnotobióticas, quanto abelhas com a microbiota intestinal convencional, e feita a comparação entre taxas de mortalidade e os níveis de resíduos de pesticidas, em cada grupo tratado com tiaclopride ou Tau-Fluvalinato, o mesmo foi feito em relação a antibióticos tetraciclina. Foi observado que abelhas gnotobióticas tiveram níveis elevados de mortalidade. Já abelhas com a microbiota convencional apresentaram maior expressão de enzimas P450 no intestino médio. Esses resultados nos levam a crer que a microbiota intestinal tem significativa contribuição no processo de desintoxicação nas abelhas e revelam os impactos negativos do uso de antibióticos nas colmeias, como já vem sendo comprovado nos estudos de Raymann, Shaffer e Moran (2017) e Motta, Raymann e Moran (2018).

Além disso, as abelhas também podem se intoxicar através da alimentação, pois alguns produtos derivados das degradações de carboidratos podem gerar açúcares tóxicos e recalcitrantes que não são metabolizados pelo hospedeiro, como monossacarídeos (manose, xilose, arabinose e ramnose) e alguns oligossacarídeos, que reduzem a sua expectativa de vida (Barker \& Lehner, 1974; Barker, 1977). Sabendo disto, o estudo conduzido por Zheng et al. (2016), buscou identificar cepas bacterianas 
com a capacidade de degradar esses açucares, onde foi observado que cepas de Giliamella apícola, bactéria presente no intestino da grande maioria das abelhas operárias, associadas ao intestino do gênero Apis são capazes de metabolizar manose, xilose, arabinose e ramnose, açúcares tóxicos a seu hospedeiro. Assim, é notório que essas cepas detêm papel importante na melhoria das tolerâncias dietéticas e na manutenção da saúde de seus hospedeiros.

\subsubsection{Desenvolvimento da imunidade e proteção contra patógenos}

Os insetos possuem mecanismos sensíveis para identificação e desenvolvimento estratégias para se defenderem patógenos. Assim, a resposta imunológica desenvolvida pelos insetos não apresenta memória, sendo dominada pela resposta imune inata e compreende três meios de defesa principal: I - Resposta humoral gerada por peptídeos antimicrobianos; II Resposta celular, onde o invasor é fagocitado e encapsulado; III - Reação da fenoloxidase ou tirosinase, que deposita pigmentos de melanina ao redor de ferimentos e objetos estranhos (Tzau, Gregorio \& Lemaitre, 2002). Destas, a resposta imunológica I e III, podem ter influência direta de bactérias intestinais de abelhas.

Uma função dos peptídeos antimicrobianos (AMPs) no intestino é a manutenção da homeostase, inibindo seletivamente as bactérias e impedindo a proliferação excessiva de bactérias nativas, as quais tendem a apresentar maior tolerância aos AMPs do hospedeiro em comparação com microrganismos não nativos (Cullen et al., 2015). Estudo fornecem evidências experimentais de uma interação entre o microbioma intestinal das abelhas e o sistema imunológico. Foram encontradas fortes suprarregulação da apidaecina AMP, bem como níveis elevados de himenoptaecina, em abelhas inoculadas com a microbiota convencional, podendo haver regulação diferencial por diferentes membros da microbiota (Kwong, Mancenido \& Moran, 2017).

Além da resposta imune através de AMPs, a microbiota intestinal também é capaz de induzir outras respostas imunológicas. Frischella perrara, uma bactéria da microbiota intestinal das abelhas, coloniza uma região restrita no piloro e induz um fenótipo chamado de sarna (Engel, Bartlett \& Moran, 2015). Este fenótipo é caracterizado por um depósito melanina, causado por dano tecidual, formando uma faixa fina localizada no piloro, na fronteira intestino médio-posterior, próximo aos túbulos de Malpighi (Nappi \& Christensen, 2005).

A presença deste faixa de melanina nas abelhas causadas por F. perrara, de acordo com Emery; Schmidt e Engel (2017), faz parte de uma pré-ativação imunológica no piloro, protegendo o hospedeiro de patógenos subsequentes. Este fenômeno é geralmente referido como imunização primária e foi demonstrado que existe em uma ampla gama de insetos, incluindo abelhas. Além disto, vários dos genes imunes induzidos por $F$. perrara codificam AMPs, que têm uma ampla atividade antimicrobiana e, portanto, provavelmente atuam contra uma ampla gama de outros microrganismo oportunistas (Bulet et al., 1999).

Outra forma de promoção da imunidade por bactérias intestinais são os biofilmes, que são comunidades de bactérias envoltas por substâncias, principalmente açúcares, produzidas pelas próprias bactérias, que conferem a comunidade proteção contra diversos tipos de agressões que ela pode vir a sofrer, como por exemplo, a falta de nutrientes, o uso de um antibiótico, proteção contra patógenos, ou algum agente químico utilizado para combater bactérias (Martinson, Moy \& Moran, 2012; Kwong \& Moran, 2013; Zheng et al., 2019).

\section{Considerações Finais}

Esta revisão reuni evidências de que a herança vertical, por meio do contato social, é uma das principais forças que moldam o microbioma das abelhas eussociais ao longo da história evolutiva. Apoiam a hipótese emergente de que as características eussociais das abelhas facilita o desenvolvimento e manutenção de microbiomas especializados, proporcionando condições ecológicas e mecanismos de transmissão confiáveis. E por fim, nos relatam os principais papéis que estes simbiontes exercem na manutenção da saúde de seu hospedeiro. Este levantamento pode ser utilizado como base para futuros estudos relacionados ao papel que as bactérias desempenham quando associadas a abelhas eussociais. 


\section{Referências}

Asenjo, F., Olmos, A., Henríquez-Piskulich, P., Polanco, V., Aldea, P., Ugalde, J. A., \& Trombert, A. N. (2016). Genome sequencing and analysis of the first complete genome of Lactobacillus kunkeei strain MP2, an Apis mellifera gut isolate. PeerJ, 4, e1950. https://doi.org/10.7717/peerj.1950.

Barker R. J. (1977). Some carbohydrates found in pollen and pollen substitutes are toxic to honey bees. The Journal of nutrition, 107(10), 1859-1862. https://doi.org/10.1093/jn/107.10.1859

Barker, R. J., \& Lehner, Y. (1974). Influence of diet on sugars found by thin-layer chromatography in thoraces of honey bees, Apis mellifera L. The Journal of experimental zoology, 188(2), 157-164. https://doi.org/10.1002/jez.1401880204

Bonilla-Rosso, G., \& Engel, P. (2018). Functional roles and metabolic niches in the honey bee gut microbiota. Current opinion in microbiology, 43, 69-76. https://doi.org/10.1016/j.mib.2017.12.009

Bottacini, F., Milani, C., Turroni, F., Sánchez, B., Foroni, E., Duranti, S., Serafini, F., Viappiani, A., Strati, F., Ferrarini, A., Delledonne, M., Henrissat, B., Coutinho, P., Fitzgerald, G. F., Margolles, A., van Sinderen, D., \& Ventura, M. (2012). Bifidobacterium asteroides PRL2011 genome analysis reveals clues for colonization of the insect gut. PloS one, 7(9), e44229. https://doi.org/10.1371/journal.pone.0044229

Bulet, P., Hetru, C., Dimarcq, J. L., \& Hoffmann, D. (1999). Antimicrobial peptides in insects; structure and function. Developmental and comparative immunology, 23(4-5), 329-344. https://doi.org/10.1016/s0145-305x(99)00015-4

Cariveau, D. P., Elijah Powell, J., Koch, H., Winfree, R., \& Moran, N. A. (2014). Variation in gut microbial communities and its association with pathogen infection in wild bumble bees (Bombus). The ISME journal, 8(12), 2369-2379. https://doi.org/10.1038/ismej.2014.68

Cruz-Landim, C. (2009). Abelhas morfologia e função de sistemas. UNESP.

Cullen, T. W., Schofield, W. B., Barry, N. A., Putnam, E. E., Rundell, E. A., Trent, M. S., Degnan, P. H., Booth, C. J., Yu, H., \& Goodman, A. L. (2015). Gut microbiota. Antimicrobial peptide resistance mediates resilience of prominent gut commensals during inflammation. Science (New York, N.Y.), 347(6218), 170 175. https://doi.org/10.1126/science. 1260580

du Rand, E. E., Pirk, C., Nicolson, S. W., \& Apostolides, Z. (2017). The metabolic fate of nectar nicotine in worker honey bees. Journal of insect physiology, 98, 14-22. https://doi.org/10.1016/j.jinsphys.2016.10.017

Emery, O., Schmidt, K., \& Engel, P. (2017). Immune system stimulation by the gut symbiont Frischella perrara in the honey bee (Apis mellifera). Molecular ecology, 26(9), 2576-2590. https://doi.org/10.1111/mec.14058

Engel, P., \& Moran, N. A. (2013). Functional and evolutionary insights into the simple yet specific gut microbiota of the honey bee from metagenomic analysis. Gut microbes, 4(1), 60-65. https://doi.org/10.4161/gmic. 22517

Engel, P., Bartlett, K. D., \& Moran, N. A. (2015). The Bacterium Frischella perrara Causes Scab Formation in the Gut of its Honeybee Host. mBio, 6(3), e0019315. https://doi.org/10.1128/mBio.00193-15

Engel, P., Kwong, W. K., McFrederick, Q., Anderson, K. E., Barribeau, S. M., Chandler, J. A., Cornman, R. S., Dainat, J., de Miranda, J. R., Doublet, V., Emery, O., Evans, J. D., Farinelli, L., Flenniken, M. L., Granberg, F., Grasis, J. A., Gauthier, L., Hayer, J., Koch, H., Kocher, S. \& Dainat, B. (2016). The Bee Microbiome: Impact on Bee Health and Model for Evolution and Ecology of Host-Microbe Interactions. $m$ Bio, 7(2), e02164-15. https://doi.org/10.1128/mBio.02164-15

Engel, P., Martinson, V. G., \& Moran, N. A. (2012). Functional diversity within the simple gut microbiota of the honey bee. Proceedings of the National Academy of Sciences of the United States of America, 109(27), 11002-11007. https://doi.org/10.1073/pnas.1202970109

Ercole, F. F., Melo, L. S. \& Alcoforado, C. L. G. C. (2014). Revisão integrativa versus revisão sistemática. Revista Mineira de Enfermagem. $18(1)$, 9-12.

Fairbrother, A., Purdy, J., Anderson, T., \& Fell, R. (2014). Risks of neonicotinoid insecticides to honeybees. Environmental toxicology and chemistry, 33(4), 719-731. https://doi.org/10.1002/etc. 2527

Forsgren, E., Olofsson, T. C., Váasquez, A., Frias, I. (2010). Novel lactic acid bacteria inhibiting Paenibacillus larvae in honey bee larvae. Apidologie 41, 99108. https://doi.org/10.1051/apido/2009065

Frias, B. E. D, Barbosa, C. D., Lourenço, A. P. (2016). Nutrição de pólen em abelhas ( Apis mellifera ): impacto na saúde adulta. Apidologie, 47, 15-25. https://doi.org/10.1007/s13592-015-0373-y

Gallai, N., Salles, J. M., Settele, J., Vaissière, B. E. (2009). Economic valuation of the vulnerability of world agriculture confronted with pollinator decline. Ecological Economics, Elsevier, 68(3), 810-821. https://doi.org/10.1016/j.ecolecon.2008.06.014

Gill, R. J., Ramos-Rodriguez, O., \& Raine, N. E. (2012). Combined pesticide exposure severely affects individual- and colony-level traits in bees. Nature, 491(7422), 105-108. https://doi.org/10.1038/nature11585

Goulson, D. (2010). Bumblebees : behaviour, ecology, and conservation, 2nd ed. Oxford University Press.

Goulson, D., Nicholls, E., Botías, C., \& Rotheray, E. L. (2015). Bee declines driven by combined stress from parasites, pesticides, and lack of flowers. Science (New York, N.Y.), 347(6229), 1255957. https://doi.org/10.1126/science.1255957

Henry, M., Béguin, M., Requier, F., Rollin, O., Odoux, J. F., Aupinel, P., Aptel, J., Tchamitchian, S., \& Decourtye, A. (2012). A common pesticide decreases foraging success and survival in honey bees. Science (New York, N.Y.), 336(6079), 348-350. https://doi.org/10.1126/science.1215039 
Kakumanu, M. L., Reeves, A. M., Anderson, T. D., Rodrigues, R. R., \& Williams, M. A. (2016). Honey Bee Gut Microbiome Is Altered by In-Hive Pesticide Exposures. Frontiers in microbiology, 7, 1255. https://doi.org/10.3389/fmicb.2016.01255

Kešnerová, L., Mars, R., Ellegaard, K. M., Troilo, M., Sauer, U., \& Engel, P. (2017). Disentangling metabolic functions of bacteria in the honey bee gut. PLoS biology, 15(12), e2003467. https://doi.org/10.1371/journal.pbio.2003467

Kešnerová, L., Moritz, R., \& Engel, P. (2016). Bartonella apis sp. nov., a honey bee gut symbiont of the class Alphaproteobacteria. International journal of systematic and evolutionary microbiology, 66(1), 414-421. https://doi.org/10.1099/ijsem.0.000736

Khan, K. A., Al-Ghamdi, A. A., Ghramh, H. A., Ansari, M. J., Ali, H., Alamri, S. A., Al-Kahtani, S. N., Adgaba, N., Qasim, M., \& Hafeez, M. (2020). Structural diversity and functional variability of gut microbial communities associated with honey bees. Microbial pathogenesis, 138, 103793 . https://doi.org/10.1016/j.micpath.2019.103793

Killer, J., Dubná, S., Sedláček, I., \& Švec, P. (2014). Lactobacillus apis sp. nov., from the stomach of honeybees (Apis mellifera), having an in vitro inhibitory effect on the causative agents of American and European foulbrood. International journal of systematic and evolutionary microbiology, 64(Pt 1), 152-157. https://doi.org/10.1099/ijs.0.053033-0

Koch, H., \& Schmid-Hempel, P. (2011). Socially transmitted gut microbiota protect bumble bees against an intestinal parasite. Proceedings of the National Academy of Sciences of the United States of America, 108(48), 19288-19292. https://doi.org/10.1073/pnas.1110474108

Kwong, W. K., \& Moran, N. A. (2013). Cultivation and characterization of the gut symbionts of honey bees and bumble bees: description of Snodgrassella alvi gen. nov., sp. nov., a member of the family Neisseriaceae of the Betaproteobacteria, and Gilliamella apicola gen. nov., sp. nov., a member of Orbaceae fam. nov., Orbales ord. nov., a sister taxon to the order 'Enterobacteriales' of the Gammaproteobacteria. International journal of systematic and evolutionary microbiology, 63(Pt 6), 2008-2018. https://doi.org/10.1099/ijs.0.044875-0

Kwong, W. K., \& Moran, N. A. (2016). Gut microbial communities of social bees. Nature reviews. Microbiology, 14(6), 374-384. https://doi.org/10.1038/nrmicro.2016.43

Kwong, W. K., Engel, P., Koch, H., \& Moran, N. A. (2014). Genomics and host specialization of honey bee and bumble bee gut symbionts. Proceedings of the National Academy of Sciences of the United States of America, 111(31), 11509-11514. https://doi.org/10.1073/pnas.1405838111

Kwong, W. K., Mancenido, A. L., \& Moran, N. A. (2017). Immune system stimulation by the native gut microbiota of honey bees. Royal Society open science, 4(2), 170003. https://doi.org/10.1098/rsos.170003

Kwong, W. K., Medina, L. A., Koch, H., Sing, K. W., Soh, E., Ascher, J. S., Jaffé, R., \& Moran, N. A. (2017). Dynamic microbiome evolution in social bees. Science advances, 3(3), e1600513. https://doi.org/10.1126/sciadv.1600513

Lee, F. J., Miller, K. I., McKinlay, J. B., \& Newton, I. (2018). Differential carbohydrate utilization and organic acid production by honey bee symbionts. FEMS microbiology ecology, 94(8), 10.1093/femsec/fiy113. https://doi.org/10.1093/femsec/fiy113

Lee, F. J., Rusch, D. B., Stewart, F. J., Mattila, H. R., \& Newton, I. L. (2015). Saccharide breakdown and fermentation by the honey bee gut microbiome. Environmental microbiology, 17(3), 796-815. https://doi.org/10.1111/1462-2920.12526

Martinson, V. G., Danforth, B. N., Minckley, R. L., Rueppell, O., Tingek, S., \& Moran, N. A. (2011). A simple and distinctive microbiota associated with honey bees and bumble bees. Molecular ecology, 20(3), 619-628. https://doi.org/10.1111/j.1365-294X.2010.04959.x

Martinson, V. G., Moy, J., \& Moran, N. A. (2012). Establishment of characteristic gut bacteria during development of the honeybee worker. Applied and environmental microbiology, 78(8), 2830-2840. https://doi.org/10.1128/AEM.07810-11

McFrederick, Q. S., Wcislo, W. T., Taylor, D. R., Ishak, H. D., Dowd, S. E., \& Mueller, U. G. (2012). Environment or kin: whence do bees obtain acidophilic bacteria?. Molecular ecology, 21(7), 1754-1768. https://doi.org/10.1111/j.1365-294X.2012.05496.x

Michener, C. D. (2000). The bees of the world. Baltimore: The Johns Hopkins University Press.

Michener, CD (2007) The Bees of the World. (2a ed.), John Hopkins University Press, Baltimore.

Michener, C. D. (2013). The Meliponini. In: Vit, P., Pedro, S. R. M., Roubik, D. H. (Orgs.). Pot-Honey: A legacy of stingless bees. New York: Springer.

Moran, N. A., Hansen, A. K., Powell, J. E., \& Sabree, Z. L. (2012). Distinctive gut microbiota of honey bees assessed using deep sampling from individual worker bees. PloS one, 7(4), e36393. https://doi.org/10.1371/journal.pone.0036393

Moran, N. A., Ochman, H., \& Hammer, T. J. (2019). Evolutionary and ecological consequences of gut microbial communities. Annual review of ecology, evolution, and systematics, 50(1), 451-475. https://doi.org/10.1146/annurev-ecolsys-110617-062453

Motta, E., Raymann, K., \& Moran, N. A. (2018). Glyphosate perturbs the gut microbiota of honey bees. Proceedings of the National Academy of Sciences of the United States of America, 115(41), 10305-10310. https://doi.org/10.1073/pnas.1803880115

Nappi, A. J., \& Christensen, B. M. (2005). Melanogenesis and associated cytotoxic reactions: applications to insect innate immunity. Insect biochemistry and molecular biology, 35(5), 443-459. https://doi.org/10.1016/j.ibmb.2005.01.014

Nogrado, K., Lee, S., Chon, K., Lee, J. H. (2019). Effect of transient exposure to carbaryl wettable powder on the gut microbial community of honey bees. Applied Biological Chemistry, 62(6), 1-8. https://doi.org/10.1186/s13765-019-0415-7

Olofsson, T. C., \& Vásquez, A. (2008). Detection and identification of a novel lactic acid bacterial flora within the honey stomach of the honeybee Apis mellifera. Current microbiology, 57(4), 356-363. https://doi.org/10.1007/s00284-008-9202-0 
Onchuru, T. O., Javier Martinez, A., Ingham, C. S., \& Kaltenpoth, M. (2018). Transmission of mutualistic bacteria in social and gregarious insects. Current opinion in insect science, 28, 50-58. https://doi.org/10.1016/j.cois.2018.05.002

Raymann, K., \& Moran, N. A. (2018). The role of the gut microbiome in health and disease of adult honey bee workers. Current opinion in insect science, 26, 97-104. https://doi.org/10.1016/j.cois.2018.02.012

Raymann, K., Bobay, L. M., \& Moran, N. A. (2018). Antibiotics reduce genetic diversity of core species in the honeybee gut microbiome. Molecular ecology, 27(8), 2057-2066. https://doi.org/10.1111/mec.14434

Raymann, K., Shaffer, Z., \& Moran, N. A. (2017). Antibiotic exposure perturbs the gut microbiota and elevates mortality in honeybees. PLoS biology, 15(3), e2001861. https://doi.org/10.1371/journal.pbio.2001861

Ryu, J. H., Kim, S. H., Lee, H. Y., Bai, J. Y., Nam, Y. D., Bae, J. W., Lee, D. G., Shin, S. C., Ha, E. M., \& Lee, W. J. (2008). Innate immune homeostasis by the homeobox gene caudal and commensal-gut mutualism in Drosophila. Science (New York, N.Y.), 319(5864), 777-782. https://doi.org/10.1126/science. 1149357

Schwarz, R. S., Moran, N. A., \& Evans, J. D. (2016). Early gut colonizers shape parasite susceptibility and microbiota composition in honey bee workers. Proceedings of the National Academy of Sciences of the United States of America, 113(33), 9345-9350. https://doi.org/10.1073/pnas.1606631113

Smagghe, G., \& Tirry, L. (2001). Insect midgut as a site for insecticide detoxification and resistance. In I. Ishaaya (Ed.), Biochemical sites of insecticide action and resistance (pp. 293-321). Berlin, Germany: Springer.

Tzou, P., De Gregorio, E., \& Lemaitre, B. (2002). How Drosophila combats microbial infection: a model to study innate immunity and host-pathogen interactions. Current opinion in microbiology, 5(1), 102-110. https://doi.org/10.1016/s1369-5274(02)00294-1

Vásquez, A., Forsgren, E., Fries, I., Paxton, R. J., Flaberg, E., Szekely, L., \& Olofsson, T. C. (2012). Symbionts as major modulators of insect health: lactic acid bacteria and honeybees. PloS one, 7(3), e33188. https://doi.org/10.1371/journal.pone.0033188

Vaudo, A. D., Tooker, J. F., Grozinger, C. M., \& Patch, H. M. (2015). Bee nutrition and floral resource restoration. Current opinion in insect science, 10, 133141. https://doi.org/10.1016/j.cois.2015.05.008

Wu, M., Sugimura, Y., Takaya, N., Takamatsu, D., Kobayashi, M., Taylor, D., \& Yoshiyama, M. (2013). Characterization of bifidobacteria in the digestive tract of the Japanese honeybee, Apis cerana japonica. Journal of invertebrate pathology, 112(1), 88-93. https://doi.org/10.1016/j.jip.2012.09.005

Wu, Y., Zheng, Y., Chen, Y., Wang, S., Chen, Y., Hu, F., \& Zheng, H. (2020). Honey bee (Apis mellifera) gut microbiota promotes host endogenous detoxification capability via regulation of $\mathrm{P} 450$ gene expression in the digestive tract. Microbial biotechnology, 13(4), 1201-1212. https://doi.org/10.1111/17517915.13579

Yoshiyama, M., \& Kimura, K. (2009). Bacteria in the gut of Japanese honeybee, Apis cerana japonica, and their antagonistic effect against Paenibacillus larvae, the causal agent of American foulbrood. Journal of invertebrate pathology, 102(2), 91-96. https://doi.org/10.1016/j.jip.2009.07.005

Yun, J. H., Jung, M. J., Kim, P. S., \& Bae, J. W. (2018). Social status shapes the bacterial and fungal gut communities of the honey bee. Scientific reports, 8(1), 2019. https://doi.org/10.1038/s41598-018-19860-7

Zheng, H., Nishida, A., Kwong, W. K., Koch, H., Engel, P., Steele, M. I., \& Moran, N. A. (2016). Metabolism of Toxic Sugars by Strains of the Bee Gut Symbiont Gilliamella apicola. mBio, 7(6), e01326-16. https://doi.org/10.1128/mBio.01326-16

Zheng, H., Perreau, J., Powell, J. E., Han, B., Zhang, Z., Kwong, W. K., Tringe, S. G., \& Moran, N. A. (2019). Division of labor in honey bee gut microbiota for plant polysaccharide digestion. Proceedings of the National Academy of Sciences of the United States of America,116(51), 25909-25916. https://doi.org/10.1073/pnas.1916224116

Zheng, H., Powell, J. E., Steele, M. I., Dietrich, C., \& Moran, N. A. (2017). Honeybee gut microbiota promotes host weight gain via bacterial metabolism and hormonal signaling. Proceedings of the National Academy of Sciences of the United States of America, 114(18), 4775-4780. https://doi.org/10.1073/pnas.1701819114

Zheng, H., Steele, M. I., Leonard, S. P., Motta, E., \& Moran, N. A. (2018). Honey bees as models for gut microbiota research. Lab animal, 47(11), 317-325. https://doi.org/10.1038/s41684-018-0173-X 